\title{
Transitioning beyond the Economic-environmental Trade-off in the City of Hangzhou
}

\section{Huang, J., W. Teng, and R. Galliers}

\begin{abstract}
This research uses the concept of ambidexterity to develop further the field of urban transformation and sustainability. Empirically, we document and conceptualize the experience of a Chinese industrialized city, Hangzhou, in overcoming the economic-ecological trade-off common in declining urban environments. We analyze Hangzhou's large-scale green initiative by examining the political, entrepreneurial and environmental rationale behind the initiative, the distinctive organizational capability that enables its implementation, and the initiative's economic and ecological impact on the city. We propose and elaborate the concept of "ambidexterity in the making" and two sets of enabling mechanisms to explain how such a unique capability is formed and functions to afford an urban government to actualize its green aspirations into an ecological reality, while simultaneously fostering entrepreneurialism and further economic development.
\end{abstract}

Keywords: ambidexterity; urban transformation; urban sustainability

INTRODUCTION 
How to make industrialised China green is no longer a subject that matters merely to the Chinese. Indeed, addressing and combating climate change represents a challenge with substantial global relevance (Lo et al., 2006). China has seen unprecedented urbanisation alongside its industrialization. As with many urban areas in developing countries, the cityscapes of China have experienced rapid and dramatic changes, all too often neglecting the consequential negative ecological and social impacts (Cohen, 2004; Muldavin, 2015; Pow and Harvey, 2013). These changes suggest a trade-off, with pollution and decline in the urban environment regularly being seen as an inevitable outcome of the process of economic development (Pow and Harvey, 2013; Véron, 2006; Xue and Luo, 2015). Few industrialized cities in developing countries, including many in $\mathrm{China}^{1}$, escape from such policy struggles as a result of this economic-environmental trade-off.

Responding to the "uneven and unjust" urban landscape is the emerging "urban sustainability" movement (Keil, 2003, 2005; Pow and Harvey, 2013; Yu and Wen, 2010) with a specific agenda to examine, collectively, the dynamic interplay amongst political regime, environmental governance and entrepreneurial activity (Gibbs, 2002; Morrison, 2014; While, et al., 2004). The rationale behind concurrently examining these three forces is twofold. First, sustainability and modernization in the urban environment are resource-draining endeavours. Therefore, environmental modernization and sustainability are complex issues for both the political and economic agendas. They need to be prioritized and reprioritized (Heynen, 2006), and require feasible economic returns to justify and maintain the capital investment required (Gibbs, 2002; Morrison, 2014). Second, environmental modernization, being

\footnotetext{
${ }^{1}$ According to the World Bank's report published in 2015, China has the worst urban air pollution in PM10 concentrations.
} 
intrinsically power-centric, has recursively resulted in socio-environmental injustice (Gandy, 2004; Harvey, 1996; Pow and Harvey, 2013; Smith, 1984), and can no longer be perceived as merely an ecological opportunity. Rather, it requires urban governments' capability, systematically, to articulate, strategically plan and effectively co-ordinate different underlying forces in order to overcome socio-environmental injustice and move beyond the economic-environmental trade-off. Reflecting on the current theorization of urban transformation and sustainability, there are studies that conceptualize how the trade-off occurs and how it prevents an urban government from escaping it (e.g. Harvey, 1996; Pow and Harvey, 2013; Véron, 2006). There are also accounts that depict the political and ecological implications once a city has moved beyond the trade-off (e.g. Gibbs, 2002; While et al., 2004). However, what is missing from current theorization is how the transition to move beyond the economicenvironmental trade-off actually takes place. To address this theoretical shortfall, this study investigates the following two research questions. First, what are the key enabling mechanisms needed to initiate and propel the continuous transition of an urban environment? Second, what capabilities would an urban government require in order to bring its green ideology and related policies to ecological reality?

The national context for this study is the People's Republic of China. Ongoing struggles and compromises highlight many of the changes in Chinese urban environments in its industrialized cities since the adoption of the "open door" policy in 1978 (Huan, 1986). Economic growth has become and still remains a top political priority for local governments (Arrighi, 2007; Morrison, 2014), often over other agendas, such as pollution control and environment protection (Lo et al., 2006; Ma and Ortolano, 2000; Xue and Luo, 2015). Despite the fact that national regulatory frameworks have been introduced, modified and reinforced, very limited continuous 
progress has been evident (Lo et al., 2006; Xue and Luo, 2015). However, there are a small, yet growing number of what might be called urban frontiers in China that are starting to tackle the economic-environmental trade-off. Similar to many “entrepreneurial cities" (Hall and Hubbard, 1998; Morrison, 2014), where economic growth is emphasized, these urban frontiers have started to take advantage of their improving urban environments as one of their main selling points in attempting to attract mobile capital, in particular foreign direct investments (FDI). The City of Hangzhou was selected as the research site, because it was recognized by World Bank and the National Development and Reform Commission as one of the most successful examples in its environmental modernization and economic growth efforts back in 2006, when we started our research. These two cities are reported to be the most environmentally improved and advanced amongst the top 20 highest GDP per capita cities in China. As the capital city of Zhejiang Province, 190 kilometres south-west of Shanghai, Hangzhou was described by Marco Polo as the most beautiful city in the world, and is one of the most popular tourist destinations in China. Hangzhou's experience, in particular its ongoing green initiative, designed to improve its urban environment, is examined and used here as a means to depict the creation of its new economic and ecological identity.

Addressing the above two research questions, our main contribution is to theorize urban government's capability to move beyond the economic-environmental trade-off. More specifically, to extend existing urban transformation and sustainability research (Gibbs, 2002; Harvey, 1989; Pow and Harvey, 2013; While et al., 2004) and to address the theoretical shortfall in conceptualizing urban government's capability to move beyond the trade-off, we draw on the perspective of ambidexterity (Gibson and Birkinshaw, 2004; Raisch, et al., 2008; Tushman and O'Reilly, 1996) to provide the 
theoretical building block. In particular, the concept of ambidexterity is incorporated into our study with a view to examine how struggles related to the economicenvironmental trade-off may be overcome. Our findings show how economic growth, as a key political objective can, instead of hampering, pave the way for the ecological sustainability of the urban environment. However, to enable the transition beyond the trade-off, our findings reveal two generative mechanisms, namely "entrepreneurial infrastructuring" and "ecological momentum". We posit that these generative mechanisms need to be created with sufficient political force and economic incentives. The findings arising from this study are not only crucial in enhancing our understanding of urban sustainability and transformation, they also serve as a valuable lesson for other cities within and outside China to consider, and from which to learn. The contributions to policy include perceiving economic development alongside ecological advancements in combination, rather than as two necessarily opposing forces.

\section{CURRRENT DEBATES AND PERSPECTIVES}

Growing interests in urban sustainability and transformation have provided several important and interesting streams of literature, each with very distinctive intellectual tradition and foci. Given that it is not feasible to exhaust them all, we have selected the concept of urban entrepreneurialism, which uniquely stresses urban economic growth in conjunction with environmental transformation, as our theoretical starting point.

\section{Urban Entrepreneurialism}

The notion of an entrepreneurial city (Hall and Hubbard, 1998) exemplifies urban governance that actively pursues the ideology of "growth first" (Peck and Tickell, 
2002). Urban entrepreneurialism is increasingly recognised as a highly relevant concept to examine the relationship between the political process, socio-economic influences and more recently, environmental change and sustainability (Pow and Harvey, 2013). This mutually constituted and potentially positively reinforcing relationship is described by While et al. (2004, p. 550) in the following terms: "urban entrepreneurialism itself might depend on the active remaking of urban environments and ecologies". They note that the importance of what they term "to green the growth machine" is reflected in the need to create confidence amongst the diverse range of stakeholders and audiences in order to ensure that an entrepreneurial city "is moving in the right direction in terms of the greening of capitalism" (p. 565).

According to Harvey (1989), urban entrepreneurialism may be achieved through one or more of four approaches: first, through efficient and effective exploitation of advantages for the production of goods and services; second, through the "spatial division of consumption", third, through "the acquisition of key control and command functions in high finance, government, or information gathering and processing (including the media)" (page 9) ${ }^{3}$, and fourth, through the redistribution of entrepreneurial opportunities, benefits and other support by central, and in many cases regional, state or local, governments. The singular, or combined, use of these four approaches depends largely on the underlying strategic intent of the urban government, as well as on the extent of mobilization and exploitation of human, political and economic resources currently, or that can effectively be made, available. The approach

\footnotetext{
2 This is concerned with raising consumption through a process of gentrification and upgrading by means of cultural innovation and other consumer attractions.

${ }^{3}$ Harvey explains that this type of urban entrepreneurialism often requires expensive infrastructural provision in areas such as transport and communications, as well as appropriate commercial spaces that may facilitate reductions in transaction costs and time.
} 
taken serves as a crucial indicator of an urban government's economic and ecological identity and aspiration.

When examining the urban contexts of China, Harvey's typology of approaches to urban entrepreneurialism provides a useful conceptual tool. Since the adoption of the “open door" policy in 1978 (Huan, 1984), attracting mobile capital to cities and regions has become a top priority for urban and provincial governments (Arrighi, 2007). As a result, competition for mobile capital is no longer between China and its neighbouring countries, it extends to cities and regions outside as well as within China (Chao, et al. 2005; Tan, 2007). Compared to other cities, such as Beijing, Shanghai and Guangzhou, which encompass all four of Harvey's (1989) approaches concurrently and extensively, many of the provincial capital cities, such as Hangzhou in this case, adopt a single or prioritised approach, due mainly to geographic, political and resource implications. Despite the differences in approach, rapid and continuous economic growth in those cities is commonly evident - but so is a worsening of the urban environment and its ecological condition (Ma and Ortolano, 2000). Even though comprehensive environmental legislation has been established, reinforced and implemented ${ }^{4}$, in particular since China joined the WTO in 2000, the impact has been negligible (Lo et al., 2006). Urban governments struggle with environmental concerns, while failing to compromise on economic growth - a situation characteristic of the trade-off introduced earlier.

In an effort to address this economic-environmental trade-off, many urban governments have resorted to displacing polluting industries to suburban or rural areas - a policy described by Harvey (1992) as "spatial fix". Clearly, however, the fact that

\footnotetext{
${ }^{4}$ For an extensive review of literature related to changes in environment reinforcement styles in China, please refer to the article by Lo et al. (2009).
} 
pollution may no longer be a problem to the urban area concerned, such a policy simply creates similar problems - one might say a socio-environmental injustice - elsewhere. The trade-off, in a different guise, remains. Conversely, While et al. (2004) point to the fact that some cities have moved beyond the trade-off. Their account showcases the new economic and environmental identities that the likes of Manchester and Leeds in the UK have created, along with entrepreneurial growth. These new identities have, however, also lead to additional political and environmental challenges, and calls for a "sustainability fix" to overcome "some of the governance dilemmas, compromises, and opportunities created by the current era of state restructuring and ecological modernization" (p. 551).

Despite of their valuable insights, what seems to be less clear from the work of While and colleagues, however, is the precise means by which the two cities have transitioned beyond the trade-off. This theoretical shortfall represents a crucial research gap that our study aims to fulfil. Specifically, while examples such as Leeds and Manchester may prove insightful with regard to the challenges facing Hangzhou and other Chinese entrepreneurial cities in the future, they are less useful in explaining the process by which political and economic momentum is gained, managed and sustained with a view to affording a transition from the economic-environmental trade-off position. To address this theoretical shortfall, we incorporate the concept of ambidexterity to provide a theoretical foundation that helps to explain how urban governments, in this case Hangzhou, may actualize their green aspirations, while simultaneously fostering entrepreneurialism and economic development.

\section{Ambidexterity to Transition beyond the Trade-off}


Many problems are associated with a prescriptive view of developing organizational capability, as in this case urban government's capability, that stems from so-called "best practice" solutions (Wagner and Newell, 2007): one size does not fit all. Indeed, differing demands and contextual conditions call for differing organizational capabilities and configurations (Eisenhardt and Martin, 2000; Ethiraj and Levinthal, 2004). This is a crucial consideration when attempting to deal with the multiple demands associated with such trade-offs as those between economic growth and environmental sustainability. When faced with such trade-offs, an organization is typically presented with two options. It can either approach the trade-off as a choice between the two (Grandy, 2009), keeping capabilities relatively unchanged, or - as we argue - it can develop or reconfigure its capabilities with a view to transitioning beyond the trade-off.

Central to transitioning beyond the trade-off is the need for concurrently developing solutions for different problems that are often conflicting in their required solutions (Andriopoulos and Lewis, 2009; Huang and Kim, 2013; Tushman and O'Reilly, 1996). For instance, March (1991) depicted the contradictory relationship between knowledge exploration and knowledge exploitation for responding to different learning needs, and the difficulty to simultaneously develop these two to support an organization's learning and overall competitiveness. As shown in the account of Adler, et al. (1999), most of organizations face the challenge of being excellent in efficiency and flexibility, simply because efficiency and flexibility require different organizational setups to function and flourish. Hence, efficiency and flexibility, as two of the core organizational capabilities, are often represented as trade-off. A growing number of research indicates that organizations, "being ambidextrous" (Duncan, 1976; Tushman and O'Reilly, 1996), can accomplish exceptional performance by simultaneously 
nurturing efficiency and flexibility (He and Wong, 2004; Huang and Kim, 2013; Huang, et al., 2014; Jansen, et al., 2009).

\section{Enabling Mechanisms of Ambidexterity}

Synthesizing prior studies on the functioning of ambidexterity, Gibson and Birkinshaw (2004) proposed the distinction between structural and contextual mechanisms. Structural mechanisms rely on the development of dual structure (Duncan, 1967; Tushman and O'Reilly, 1996), so that an organization can create distinct units or functions each with a clear focus on specific part of the demands. For instance, while production units are structured to develop and fully maximize efficiency, units, such as R\&D, are for handling tasks, which have a much higher level of uncertainty (Adler, et al., 1999; Grant, 1996). Even though structural mechanisms seem to be able to provide useful explanation to many ambidextrous organizations, Gibson and Birkinshaw (2004) argue that these alone are not sufficient. Instead, "contextual mechanisms" are also required to afford "the behavioral capacity to simultaneously demonstrate alignment and adaptability across an entire business unit" (p. 209). When contextual mechanisms are in place, Gibson and Birkinshaw suggest that ambidextrous organizations are able to demonstrate the capabilities of alignment and adaptability. While the former refers to the level of coherence between an organization's strategic goals and abilities to accomplish these goals' the latter represents the capability to adjust and reconfigure internal processes to effectively to meet changing demands and circumstances.

Later studies, such as Jansen, et al. (2009) and Huang, et al. (2014), also reinforce Gibson and Birkinshaw's (2004) argument that structural mechanisms alone are not sufficient to accomplish ambidexterity. This is largely due to the fact that 
structural mechanisms cannot fully comprehend the need to "mobilize, coordinate, and integrate dispersed contradictory efforts, and to allocate, reallocate, combine, and recombine resources and assets across dispersed exploratory and exploitative units" (Jansen, et al., 2009, p. 806). Therefore, developing other mechanisms, specifically those related to individual characteristics and cognitive capabilities, to supplement structural mechanisms is clearly needed (Huang and Kim, 2013; Raisch, et al., 2008). Indeed, accounts such as, Smith and Tushman (2005), Kang and Snell (2009) and Huang and Kim (2013), commonly pinpoint the fact that individuals' cognitive abilities to comprehend and address contradictory situations can play a vital role in explaining how ambidextrous organizations are able to successfully act and react according to their environments.

\section{Theorizing Ambidexterity in Urban Transformation and Sustainability}

Despite the fact that prior studies have provided very useful insights, the concept of has not yet been extensively examined and theorized in the field of public management in general and in the context of urban transformation and sustainability more specifically. This has certainly provided some theoretical opportunities, as well as challenges. What we have learned from the critical reflection of ambidexterity literature is twofold. First, ambidexterity is contingent to the external environment where organizations operate. Hence, it is a capability, which may represent very different meanings and implications when considered in different social contexts. Second, following the advice from prior studies, such as Jansen, et al. (2009) and Huang, et al. (2014), it is equally clear that ambidextrous organizations might require more than just the structural mechanisms. Rather, by taking into account its context dependence, we can safely assume that more than one set of mechanisms might be 
required. Therefore, a vital task in theorizing ambidexterity will be to identify these mechanisms and understanding how they individually and collectively contribute to the development and functioning of ambidexterity.

Drawing on this concept of ambidexterity, we now outline the methodological consideration behind the process of examining the experience of Hangzhou and its attempts to transform and sustain its urban environment while simultaneously fostering economic growth.

\section{METHODS}

The research undertaken for this paper was part of a large longitudinal study that has been investigating Hanzhou's on-going institutional change in conjunction with urban reform. In this section, we detail the research context, data collection processes and data analysis.

\section{Research Context}

The Hangzhou Municipal Government comprises 8 urban districts, 3 countylevel cities and 2 counties, all occupying a total area of 16,596 square kilometres and with a total population of close to 9 million people. Hangzhou was selected as our case to study ambidexterity for the following two reasons. First, similar to many large cities in China that have benefited from substantial economic development in the past three decades, continuous growth in Hangzhou is expected. Nevertheless, like many industrialised cities in China, Hangzhou has encountered very similar challenges in its ongoing economic development. Intensified competition nationally and regionally across East and South-east Asia has made mobile capital, in particular FDI, harder to attract and secure (Tan, 2007). Nationally, the trend is that costal cities and provinces 
are gradually experiencing a diminishing competitive edge, as the costs of land and labour are significantly higher than in the inner regions (Chao et al., 2005; Muldavin, 2015; Wong, 2007).

Second, fostering continuous economic growth represents only one aspect of the challenges encountered by many industrialised cities in China. Alongside unprecedented industrialisation and urbanisation, many Chinese cities have witnessed a sharp decline in their urban environments, often at an alarming rate. With a very small number of recent exceptions, such as Hangzhou and Suzhou, environmental problems continue to worsen. Hence, the underlying challenge is not merely about economic growth that needs to be ensured, but also about how to escape from and move beyond the economic-environmental trade-off. This has made the experience of Hangzhou potentially extremely valuable.

\section{Data Collection}

We have collected extensive longitudinal data mainly from three sources, namely interviewing, documentation and informal dialouge. Of the 103 semi-structured interviews conducted with 78 officials from the municipal and district governments ${ }^{5}$, 17 individuals were interviewed twice and four of them were interviewed three times. 31 interviewees were directly involved in or had roles related to the "Green Hangzhou" initiative. All data for this paper were collected between September 2007 and February 2013. Of the 103 interviews, 26 were conducted in Hangzhou, and 77 were conducted during training courses held in the UK. In addition to the interviews, published and unpublished materials, such as internal documents, were systematically reviewed to provide added context. The mean interview length was 54 minutes. Almost one third of

\footnotetext{
${ }^{5}$ The list of interviewees is available based on request.
} 
the interviews were recorded under permission and transcribed. Notes were taken during all interviews to capture the key points. Our study also included documents and archival data in the forms of reports, statistics, websites, policy papers, planning logs, meeting minutes, presentation materials, and training guidelines. Finally, we have collected extensive data through informal dialouge with all our interviewees. This method was found to be particularly effective, as many interviewees did not appear comfortable during the interviews.

\section{Data Analysis}

Considering the importance of iterating between data collection and analysis (Kaplan and Orlikowski, 2013; Orlikowski, 1993), we have simultaneously performed these two research processes. Despite the fact that the general orientation of this research is for generating a new theory, we have adopted the grounded theory approach (Strauss and Corbin 1998), specifically its coding techniques to analyze our collected data based on the following two steps.

Firstly, we used the technique of open coding to go through our entire dataset. Due to the vast volume of data, in particular documentation, part of our effort was to manage the data through open coding. We focused specifically on articulating, filtering, and naming all empirical evidence into distinctive concepts. After cross-checking and comparison between two researchers, 127 concepts have been created, but only 31 were retained due to their relevance to this paper's main theme. These 31 concepts were grouped into 10 different categories. Along side the open coding process, we also constructed a case storyline to capture and chronologically presented the case's progression.

During the second step, we conducted axial coding (Strauss and Corbin, 1998) 
to identify relevance and interconnection between concepts and categories developed during the previous step. Part of the axial coding was to raise questions, such as 'what capabilities have been developed? How these capabilities evolve over time? Why such capabilities were needed? What mechanisms have been developed as a result? The strengths of axial coding for data analysis in general, and for exploring interrelationship between emerging concepts more specifically, are well documented (see, for example, Henfridsson and Yoo, 2014). Our emphasis was to unpack the empirical relevance and conceptual meanings of all remaining 31 concepts and 10 categories in relation to the concept of ambidexterity. During this phase of coding, we have identified 2 different sets of mechanisms in affording ambidexterity. We then used these 2 sets of mechanisms, which were then used to reconsider all the remaining concepts and categories. This process enables us to further explore theoretical relationships that were not identified in the earlier step. We developed Figure 1 and Figure 2 to present each set of mechanisms. The quality of data analysis was ensured through iteratively comparing the emerging mechanisms with case evidence and existing literature related to ambidexterity, policy implementation and transformation. This step ended when theoretical saturation was reached. To enhance the trustworthiness and representativeness of our findings, we also obtained feedback from 4 of our interviewees.

\section{CASE- THE GREEN HANGZHOU INITIATIVE}

Hangzhou's decision simultaneously to develop its local economy, while protecting its urban environment was not coincidental. Hangzhou's outstanding scenic beauty has long been reflected in a highly popular old Chinese saying, "In heaven there is a paradise, and on earth there are Suzhou and Hangzhou". With idyllic attractions, 
such as West Lake and Xixi National Wetland Park, and a rich history spanning over 2000 years, Hangzhou has been one of the most popular tourist attractions in China for centuries. However, the radical decline in its environmental conditions, most noticeably during the 1980s and '90s, has significantly affected and endangered its long established tourism industry. As indicated by several interviewees, the efforts and resources devoted by the Hangzhou Municipal Government started in the late 1990s were as much to prevent the environmental decline as to rescue its tourism industry. The efforts in the late 1990s have shaped a vital foundation for the later urban modernization and green projects - in particular the Green Hangzhou initiative - to build on. In Hangzhou, continuously expanding the revenue streams based on the newly defined localized economic and cultural identity, in particular from the tourism industry, has gradually yielded encouraging results. For instance, in 2012, the total economic output of the tourism industry reached 139.2 billion yuan $^{6}$, an increase of $17 \%$ compared to 2010 . Such output is expected to reach 200 billion by the end of 2015 , according to a KPMG report. Capitalizing on distinctive cultural features and traditions echoes Harvey's (1989) notion of "spatial division of consumption" and an organisation's ability to deliver on its differential potential. Compared with the sole focus on economic growth (the dominating paradigm in most of cities in China), the new ideology, to concurrently develop the economy while sustaining the environment, has started to be embraced by a small number of what we term urban frontiers.

Amongst the small number of these urban frontiers, Hangzhou has been recognized by the National Development and Reform Commission as one of the most successful and innovative in its modernization initiative. Based on a number of different criteria, such as the level of attractiveness, the level of suitability for living, and the

\footnotetext{
${ }^{6}$ Approximately 15.66 billion US dollars.
} 
level of infrastructure for innovation, Hangzhou scores exceptionally well compared with all other frontier cities in China (World Bank, 2014). Hangzhou was selected by the New York Times as one of the 41 must-visit places in the world back in 2011. Indeed, our interviewees expressed pride in the recognition by central government that views Hangzhou as the role model for urban modernization and environmental sustainability, notwithstanding the need for further improvements.

Amongst various modernization projects initiated in Hangzhou, several are within or related to the broad category of environmental improvement and pollution management, and come under the umbrella initiative of Green Hangzhou. Compared with some of the green initiatives that are solely ecologically focused (e.g. Ernstson and Sörlin, 2009; Evans, 2004), the Green Hangzhou initiative, as several interviewees indicated, is based on a principle of mutual reinforcement between the sustainability of urban environment and continuous growth in economic prosperity.

We learned from our interviews that the rationale behind the Green Hangzhou initiative is threefold. First, given the important contribution of the tourism industry to the local economy and the room for further growth, the overall policy direction is to further capitalize on, and at the same time protect, Hangzhou's outstanding scenery and rich history. Second, to sustain Hangzhou's ability to attract capital investment, the aim is to recreate and promote the city as the best place in which to work and live in China. In particular, changing investment patterns amongst Chinese-speaking investors, primarily from Hong Kong and Taiwan, have seen a fast growing number of businesses reallocating their production facilities, research and development, and in many cases headquarters to China, in particular clustering in the area of Yangtze River Delta (Hangzhou Statistic Bureau, 2012). As a result, there is a growing demand for urban environments where living conditions are as attractive as the commercial infrastructure. 
Third, given that mobile capital is intended to boost job opportunities, and the availability of skilled workforce influences investment decisions, Hangzhou is actively positioning itself as the most attractive migrant destination for a skilled workforce from other cities both from within and outside China ${ }^{7}$.

According to our interviewees, the blueprint for Green Hangzhou was drawn up based on the various entrepreneurial and environmental sustainability initiatives of each of the city's districts. Essentially, the city's policy is to permit each district to develop its own initiatives, based on local social and economic circumstances. The approach provides room for districts to develop in accordance with local needs and aspirations, yet directs them to meet the environmental targets that are set for Hangzhou as a whole.

Starting in 2007, the ongoing improvement of public transportation was initiated and positioned as one of the key driving forces to actualize the Green Hangzhou initiative. As our interviewees often suggested, the most important element was the introduction of a more integrated and systematic approach towards planning, construction and management of transportation. As shown in several internal reports, prioritising and increasing investment in public transportation has led to a significant increase in the need for financial resources. Compared with 2006, the total transportation budget for 2007 reached the level of one billion yuan (US \$146 million) - a tenfold increase.

The overall project includes the construction of a metro system; enhancement of existing road network; clean-up of extensive waterways, and expansion of bus and bicycle lanes. Crucially, as noted by four of our interviewees, the integration of these separate projects has also been a top priority.

\footnotetext{
${ }^{7}$ Source: Minutes of an internal FDI review meeting held on $12^{\text {th }}$ September 2012.
} 
As noted by the project leader for the bicycle rental service, the creation and extension of dedicated bus lanes has shortened travel times across the city, compared with the use of private cars. In large part due to the new bus lanes, the average speed of buses during peak hours has reached $26.5 \mathrm{kph}$, as compared to $11.2 \mathrm{kph}$ by private vehicles ${ }^{8}$. Additionally, the growing number of buses with air-conditioning has made the experience of travelling by bus much more pleasant than previously.

There has also been a considerable increase in green spaces in the urban districts. Towards the end of 2014 , the total green space for Hangzhou as a whole reached 13,500 hectares, equating to 15.6 square meters per capita. The proportion of green space in the built-up areas of Hangzhou has increased to $42 \%$ compared with 2004, making Hangzhou one of the greenest cities in China, according to the Hangzhou Environment Department. However, what seems to be most visible to the public is the improvement in air quality; something we ourselves experienced during various visits to Hangzhou. In 2014, the number of days when air quality reached level $\mathrm{II}^{9}$ or above in urban areas of Hangzhou totalled 227 out of 365, 7.7\% improvement compared with 2013. This is in stark comparison with many Chinese cities, such as Beijing and Shanghai, where seeing direct sunlight is increasingly a rarity.

Hangzhou's street makeover project includes the introduction of unified colour, size and style for road signs, billboards, bus stops and bicycle rental stations. Based on the notion of "city furniture", as practised by the city planners, any new addition to the existing landscape has to be in keeping with the historical landmarks and surroundings, in order for it to receive planning permission. To make sense of those changes, the

\footnotetext{
${ }^{8}$ Source: an internal report of Public Transportation Group published in 2012.

${ }^{9}$ According to China's National Ambient Air Quality Standard GB 3095-1996, Level II air quality is defined based on below the annual average of $0.06 \mathrm{mg} / \mathrm{m}^{3}$ in SO $\mathrm{S}_{2}, 0.2 \mathrm{mg} / \mathrm{m}^{3}$ in TSP, $0.1 \mathrm{mg} / \mathrm{m}^{3}$ in $\mathrm{PM}_{10}, 0.05 \mathrm{mg} / \mathrm{m}^{3}$ in NOx, $0.04 \mathrm{mg} / \mathrm{m}^{3}$ in $\mathrm{NO}_{2}$, and $1.5 \mu \mathrm{g} / \mathrm{m}^{3}$ in Pb; hourly average of $10 \mathrm{mg} / \mathrm{m}^{3}$ in $\mathrm{CO}$ and $0.16 \mathrm{mg} / \mathrm{m}^{3}$ in $\mathrm{O}_{3}$.
} 
following section outlines Hangzhou's accomplishments in relation to other cities in China and describes the organizational capability that has enabled the plans to become a reality.

\section{ANALYSIS AND DISCUSSION}

During the past decade of effort and extensive investment in modernizing its urban environment, Hangzhou has achieved and sustained a leading position in comparison with other cities in China. For example, Hangzhou has continuously ranked by World Bank as No. 1 in the categories of "investment environment", "best commercial city", and "happiest city" in China during the past 10 years. Also, with a life expectancy of 80.26 years that is the highest in China and compares favourably with the national average of 73 years ${ }^{10}$, such league table standings as these have provided Hangzhou with a powerful rhetoric to shape and project its message of a new urban identity. The capability that enables Hangzhou to accomplish this ecologicaleconomic progression is worth investigating.

\section{Ambidexterity in the Making}

To conceptualize Hangzhou's continuous journey and efforts, we propose the notion of "ambidexterity in the making" to depict an urban government's capability in prospering economic growth yet at the same time enhancing its ecological accomplishments. We argue that such a capability is unique and distinct, because it affords the case organization to transition beyond the economic-environmental tradeoffs that many cities both within and outside China fail to overcome. Also, we believe that it is a capability constantly in the making for two reasons. First, ambidexterity as

\footnotetext{
${ }^{10}$ Source: http://eng.hangzhou.gov.cn/main/zpd/English/CityNews/T329711.shtml
} 
an organizational capability does not remain unchanged. Second, more ongoing efforts are still required to put Hangzhou in the same league as other leading green entrepreneurial cities. For instance, even though the results achieved by Hangzhou have provided the city with some distinctive entrepreneurial selling points, two of the interviewees, including the leader of the initiative and the chair of the steering committee, stressed the fact that many of the stakeholders have been heavily driven by the need to perform well in the league tables. Despite the fact that focusing solely on league table performance has inevitably created a competitive mentality, it is crucial for to avoid "what gets measured is what gets resourced", as several of our interviewees indicated.

\section{Enabling Mechanisms of Ambidexterity}

We have identified two sets of mechanisms that enable the functioning of ambidexterity, namely “entrepreneurial infrastructuring” and "ecological momentum". Despite the fact that these two sets of mechanisms have been analytically separated, their importance for the functioning of ambidexterity is indeed interconnected. We elaborate each in turn.

\section{Entrepreneurial Infrastructuring}

Given the growing intensity of competition for stimulating and sustaining economic growth within different parts of China and other emerging economies in the region, the sense of urgency to create a distinctive entrepreneurial identity through urban modernization is clear. Following Pipek and Wulf (2009), we use the term "infrastructuring" to indicate that both hard and soft infrastructure for an urban environment cannot be perceived as something that is constructed and once for all. 
Rather, it is an ongoing journey, which requires constant learning, adjustments and renewal to effectively address the changing demands.

The mechanism of entrepreneurial infrastructuring is found to consist of three distinctive yet interrelated elements, including "transformative gentrification", "centralized flexibility" and "mass customization". We present their theoretical relationship in Figure 1, and explain these three conceptual elements in turn.

\section{Inssert_Figure 1 about herere}

\section{Transformative gentrification}

Highly polluted industries, while many of them were crucial in boosting economic growth, have become one of the most challenging nightmares for any urban government to initiate and sustain ecological reform. Gentrification is therefore a brutal yet highly risky approach. In other words, while it might be feasible to remove these highly polluted industries, what can be replaced with to effectively change the industrial landscape and generate economic output might require careful planning and take extremely long time to materialize. Indeed, as two of our interviewees mentioned, to ensure economic growth, many cities are reluctant to strictly enforce their pollution management policies. By contrast, enforcement in Hangzhou is far more rigorous than in many of its counterparts. While taking such stringent action might not necessarily work in other urban contexts, particularly outside China, such an approach appears to work in the Chinese context, given its history of state authority and control (Ma and Ortolano, 2000). As often stressed by several interviewees, there is a strong 'can do' and 'must happen' attitude that captures the determination of the regime in driving progress and efficiency. 


\section{Centralized flexibility}

We use the term centralized flexibility to indicate the distinctive structure which provides the organization with a very high degree of efficiency without compromising the required level of flexibility to implement the green initiative in general and fostering ambidexterity more specifically. As suggested by Donaldson (2001), a highly centralized organizational structure with a high level of overall control eases the development of efficiency, compared with a decentralised or federal one. This is because tasks can be effectively differentiated and integrated, and because the need for coordination and negotiation to reach consensus is greatly reduced. This provides useful theoretical support as to how the highly centralized governance structure in Hangzhou has become such an important driving force in facilitating the development of efficiency in its urban modernization efforts, despite its highly ambitious scale and broad scope.

The centralized governance structure also directly impacts processes of simplifying the complexities associated with the scope of integration. All our interviewees commented that strong leadership, championing the initiative, has lead to all stakeholders, from diverse divisions of the municipal and district governments, to work towards a shared strategic goal. This 'top-down' leadership has created a strong driving force to secure the green initiative as the common priority, thereby greatly reducing the need for managing the kind of complexity commonly associated with the scope of integration. Given that, in this case, being adaptive is centrally coordinated and controlled, ensuring flexibility of implementing the green initiative is less challenging and time consuming than might otherwise be the case. 


\section{Mass Customization}

Another crucial aspect commonly suggested by our interviewees is the concurrent development of service-savvy citizens and customer-oriented public service providers. We use the term mass customization to indicate the long-termed goal that Hangzhou is striking to accomplish. Despite the notion of "serving the public" has long been at the core of Chinese political ideology (Tan, 2007), a customer orientation has not. While the former emphasises the availability of services, often in a 'one-size-fitsall' manner, the latter focuses on addressing and satisfying different needs. While the emphasis was largely placed on the efficiency of getting services established, the emphasis on service quality inevitably became secondary, and in many cases was overlooked. Two interviewees highlighted the point that cost efficiency had been a dominating issue in catering for the majority, rather than accommodating the growing set of diverse requirements of different demographic groups. The lack of established mechanisms and procedures had made monitoring, evaluating and enhancing the quality of service delivery infeasible. One of the interviewees stated that the need to foster cross-agency could not be isolated from the education of service-savvy citizens or service providers.

\section{Ecological Momentum}

The example of Hangzhou, specifically its efforts, investments and achievements in modernizing its urban environment, does not necessarily put it into the same league as cities, such as Copenhagen, Stockholm and Zurich, that Hangzhou has benchmarked. However, what can be taken from this case is how an ecological momentum can be created; one that provides a launching pad for further ecological progression to take place. The ecological momentum not only symbolizes 
improvements in physical aspects of the urban environment, such as with respect to air quality, green space and public transportation, but also signposts the occurrence and existence of a "green ideology" within the urban government. In addition to the importance of green ideology, we also identified the needs for the extensive promotion of "citizen-centric rhetoric" through "distributed participation". We present their theoretical relationship in Figure 2, and explain these three conceptual elements in turn.

\section{Inssert_Figure_2 about herere}

\section{Green ideology}

The emergence of a green ideology serves as a key point in tracing an urban government's strategic intent to move beyond economic-environmental trade-offs. Perceiving becoming green as a learning curve - an on-going journey (While et al., 2004) - the level of maturity demonstrated by Hangzhou is perhaps less noticeable as compared with other post-industrialized cities in developed countries. Nevertheless, it provides an excellent demonstration of the point that, without creating its ecological turning point, such cities as Hangzhou are likely to remain trapped in the trade-off position. Hangzhou's experience in creating its ecological turning point is important for two reasons. First, while the dominating paradigm in China is still centred on economic growth, the rare example of Hangzhou is both encouraging and valuable. Hangzhou's experience demonstrates that an industrialized city in China can indeed become green while benefiting economically from its green initiatives. Second, with relatively homogenous political contexts and economic aspirations, lessons learned from Hangzhou are particularly relevant to other cities in China. Thus, solutions yielded from 
the Hangzhou experience can potentially be more applicable in the Chinese context than lessons taken learned from elsewhere.

\section{Citizen-centric rhetoric}

To sustain the city's economic growth concurrently with its environmental improvement, it is crucial to continuously innovate and build on what Hangzhou has already achieved. In particular, to sustain the ecological progress will require fundamentally addressing certain underlying problems. Our interviewees cited, for example, the development of what Light (2003, p. 58) terms "urban ecological citizenship": the enablement of "public participation in the maintenance of natural processes in cities". The current underdevelopment of urban ecological citizenship indicates that further progress is yet to be made. As an example, two interviewees pointed to the issue that being protective towards the environment is yet to become widely embraced by certain parts of the urban government, let alone the citizenry. In particular, in a society where the accumulation of individual wealth is highly valued (Tan, 2007), room for progressing the urban government's green ideology and related policies into a widely accepted and embraced public ideology is understandably limited. Such an understanding is also reflected in the rationale underlying the planning and promotion of Green Hangzhou, and the emphasis on the shaping of a rhetoric to promote the initiative. As one interviewee informed us, instead of positioning Green Hangzhou as an initiative primarily to address environmental issues, the foci are purposefully placed on the transportation, health and leisure benefits, and improvement in living conditions. These are the kind of improvements with which individual citizens identify. 


\section{Distributed participation}

We use the term distributed participation to suggest the need for different stakeholders to take part, and the importance of fundamentally changing the way by which such engagement is developed and managed. Starting in 2007, incorporating citizens' inputs and suggestions into the planning process was systematically introduced through approaches such as public consultations, focus groups and questionnaires. As one interviewee explained, even though these approaches are yet to be fully routinized across the entire city, some useful results were already emerging. For instance, focus groups have been used to understand citizens' needs in planning the cycling routes and allocating rental services. While some of the suggestions required very little in the way of resources, many were overlooked by the planners. Despite the fact that the departmentalization of agencies remains largely unchanged, the crossagency units mentioned above have become more prominent and have had an impact. In conjunction with the advent of cross-agency arrangements, the standardisation of service procedures; the training of customer representatives; the development of public service help lines, and the development of measures for monitoring and evaluating services have all now been initiated. Even though the learning curve remains steep, these initiatives have helped to provide a useful building block on which the ecological momentum can be formed and sustained.

\section{CONCLUSIONS}

Reflecting on the economic growth and environmental improvement challenges faced by Hangzhou, and indeed by many industrialised cities of China, it is clear that the two aspects do not have to be approached as an either-or choice. Despite the fact that tension between economic growth and a sustainable environment is mounting, a 
small number of urban governments in China are starting to see economic incentives to transition beyond the trade-off to pursue simultaneous development of both, in particular through the improved tourism industry. The case of Hangzhou illustrates the point that transitioning beyond the economic-environmental trade-off provides the city with a significant differential advantage which other cities in China have yet to realise. The approach taken by Hangzhou reflects the point that urban entrepreneurialism is increasingly moving towards the creation of a renewed and green urban environment where living and ecological conditions are developed and attractive along with a city's industrial strengths and infrastructure. Empirically, our contribution is to elaborate the case that a greener urban environment has begun to improve Hangzhou's entrepreneurial attractiveness for mobile capital and a skilled workforce, as well as to revitalise its tourism industry. While we may not argue that other cities can simply copy Hangzhou, quickly catching up with its ecological progress, we may safely say that their similar economic and political contexts mean that many have the potential and capability to initiate green programmes of a similar nature. The lessons learned from the Hangzhou case may be amended and applied in such contexts.

Using the case of Hangzhou and its flagship green initiative, our main theoretical contribution is to present the idea of how the mechanisms of "entrepreneurial infrastructuring" and "ecological momentum" have been created to afford the functioning of ambidexterity. Despite the fact that there is still plenty of room for improvement, as reflected in our proposed notion of "ambidexterity in the making", what has been accomplished by Hangzhou serves as a launch pad for further ecological progression. The mechanisms of entrepreneurial infrastructuring and ecological momentum are not simply made up of physical improvements in the urban environment, but is characterized by the actual occurrence and existence of a green 
ideology. The concept of ambidexterity in general and the two enabling mechanisms more specifically provides an important extension to the existing intellectual landscape of urban transformation and sustainability. Hangzhou's experiences may well not be particularly meaningful when applied to cities that have already travelled some way on the green learning curve. However, these experiences may mark a new beginning where a green ideology is gradually actualized into an ecological reality.

Our account echoes the argument that "the relation between urban entrepreneurialism and the search for an urban sustainability fix is becoming a necessary rather than contingent condition of the contemporary political and economic form of urbanization in capitalism" (While et al., 2004, p. 554). Using the concept of ambidexterity, one of our main theoretical contributions is to demonstrate the point that the underlying challenge is not merely about reinforcing environmental policies; nor is it merely about the displacement of heavy polluters. Rather, it calls for an encompassing organizational capability that simultaneously addresses contradictory challenges. As shown in this case, even though a highly centralized political regime eases the development of efficiency essential to address the speed of transformation, it also has its potential downsides. These downsides are often associated with the lack of participation and stakeholder commitment. For instance, in this case, the lack of awareness and general appetite for environmental protection would not favor political rhetoric that is solely focused on green issues. Nevertheless, urban ecological citizenship (Light, 2003) is needed for further progress beyond the ecological turning point. To continue the progress, the requirement is not merely to solve in a reactive manner environmental problems that already exist. Rather, it demands fundamental changes in socio-political and economic-ecological relationships. Certainly, further research on how political and economic forces can lead to the actualization of urban 
entrepreneurialism and sustainability in different contexts is warranted. Research on other industrialised urban contexts in evaluating the trajectory of the economicecological trade-off relationship, how different political and environmental governance structure shapes and reshapes the trade-off, and how the organizational capabilities of different stakeholders contribute to the sustainability of urban ecology, would all appear to be fruitful. The current study provides a strong basis on which this research agenda can be based.

\section{REFERENCES}

Adler P, Goldoftas B, Levine D, 1999, "Flexibility versus efficiency? A case study of model changeovers in the Toyota production system" Organization Science $\mathbf{1 0}$ 43-68.

Andriopoulos C, Lewis M W, 2009, "Exploitation-exploration tensions and organizational ambidexterity: Managing paradoxes of innovation" Organization Science 20 696-717.

Arrighi G, 2007 Adam Smith in Beijing: Lineages of the Twenty-First Century (Verso, London)

Chao C, Chou W L, Yu, E S H, 2005, "Regional attributes, public inputs and tax competition for FDI in China", in Critical Issues in China's Growth and Development Eds Y K Kwan, E S H Yu (Ashgate, Aldershot) pp. 83-96

Cohen B, 2004, "Urban growth in developing countries: a review of current trends and a caution regarding existing forecast" World Development 32 23-51

Donaldson L, 2001 The Contingency Theory of Organizations (Sage, Thousand Oaks, CA) 
Duncan R, 1976, "The ambidextrous organization: Designing dual structures for innovation: In Kilmann R, Pondy L, Slevin D, Eds. The Management of Organization. North-Holland, New York.

Eisenhardt K M, Martin J A, 2000. "Dynamic capabilities: what are they?" Strategic Management Journal 21 1105-1121

Ernstson H, Sörlin S, 2009, "Weaving protective stories: connective practices to articulate holistic values in the Stockholm National Urban Park" Environment and Planning A 41 1460-1479

Ethiraj S K, Levinthal D, 2004, "Bounded rationality and the search for organizational architecture: an evolutionary perspective on the design of organizations and their evolvability" Administrative Science Quarterly 49 404-437

Evans J P, 2007, "Wildlife corridors: an urban political ecology" Local Environment $12129-152$

Gandy M, 2002 Concrete and Clay: Reworking Nature in New York City (MIT Press, Cambridge, MA)

Gandy M, 2004, "Rethinking urban metabolism: water, space and the modern city" City $8363-379$

Gibbs D, 2002 Local Economic Development and the Environment (Routledge, London)

Gibson C B, Birkinshaw J, 2004, "The antecedents, consequences, and mediating role of organizational ambidexterity" Academy of Management Journal 47 209-226

Grandy C, 2009, “The 'efficient' public administrator: Pareto and a well-rounded approach to public administration" Public Administration Review 69 1115-1123

Grant R, 1996, "Prospering in dynamically-competitive environment: organizational capability as knowledge integration” Organization Science 7 375-387 
Hall T, Hubbard P, 1998 The Entrepreneurial City (Wiley, Chichester)

Harvey D, 1989, "From managerialism to entrepreneurialism: the transformation of urban politics in late capitalism" Geografiska Annaler 7 3-18

Harvey D, 1996 Justice, Nature and the Geography of Difference (Blackwell, Oxford)

Harvey D, 1982 The Limit to Capital (Blackwell, Oxford)

He X L, Wong P K, 2004, "Exploration vs. exploitation: An empirical test of the ambidexterity hypothesis" Organization Science 15 481-494.

Henfridsson O, Yoo Y, 2014, “The liminality of trajectory shifts in institutional entrepreneurship" Organization Science 25 932-950.

Heynen N, 2006, "Green urban political ecologies: towards a better understanding of inner-city environmental change" Environment and Planning A 38 499-516

Huan G, 1986, “China’s open door policy, 1978-1984” Journal of International Affairs 39 1-18

Huang J, Newell S, Huang J S, Pan S L, 2014, "Site-shifting as the source of ambidexterity: The strategy-as-practice perspective" Journal of Strategic Information Systems 23 29-44.

Huang J, Kim H J, 2013, “Conceptualizing structural ambidexterity into the innovation of human resource management architecture: The case of LG Electronics" The International Journal of Human Resource Management Journal 24 922-943.

Jansen J, Tempelaar M P, van den Bosch F, Volberda H W, 2009, "Structural differentiation and ambidexterity: The mediating role of integration mechanisms" Organization Science 20 797-811.

Kaïka M, 2003 City of Flows: Modernity, Nature and the City (Routledge, London) Kaplan S, Orlikowski W, 2013, "Temporal work in strategy making” Organization Science 24 965-995 
Keil R, 2003, "Progress report- urban political ecology" Urban Geography 24 723-738

Keil R, 2005, "Progress report- urban political ecology” Urban Geography 26 640-651

Lawrence P, Lorsch J, 1967 Organisation and Environment: Managing Differentiation and Integration (Harvard University Press, Boston)

Light A, 2003, “Urban ecological citizenship" Journal of Social Philosophy 34 44-63

Lo C, Fryxell G, Van Rooij B, 2009, "Changes in enforcement styles among environmental enforcement officials in China" Environment and Planning A $4 \mathbf{1}$ $2706-2723$

Lo C, Fryxell G, Wong W, 2006, "Effective regulations with little effect? The antecedents of the perceptions environmental officials on environmental effectiveness in China" Environment Management 38 388-410

Ma X, Ortolano L, 2000 Environmental Regulation in China: Institutions, Enforcement, and Compliance (Rowman and Littlefield, Totowa, NJ)

Morrison N, 2014, "Building talented worker housing in Shenzhen, China, to sustain place competitiveness" Urban Studies 51 1539-1558

Muldavin J, 2015, “Using cities to control the countryside: An alternative assessment of the China national human development report 2013" Development \& Change 46 993-1009

Orlikowski W J, 1993, “CASE tools as organizational change: Investigating incremental and radical changes in systems development" MIS Quarterly 17 309340.

Peck J, Tickell A, 2002, "Neoliberalizing space” Antipode 34 380-404

Pipek V, Wulf V, 2009, "Infrastructuring: Toward an Integrated Perspective on the Design and Use of Information Technology" Journal of the Association for Information Systems 10 Article 1. 
Pow C P, Harvey, N, 2013, “Seeing red over green: Contesting urban sustainabilities in China" Urban Studies 50 2256-2274.

Raisch S, Birkinshaw J, 2008, “Organizational ambidexterity: Antecedents, outcomes, and moderators" Journal of Management 34 375-409.

Rosenthal U, Kouzmin A, 1997, "Crises and crisis management: towards comprehensive government decision making" Journal of Public Administration Research \& Theory 7 277-304

Schmink M, Wood C, 1987, “The 'political ecology' of Amazonia”, in Lands at Risk in the Third World: Local-Level Perspectives Eds P D Little, M M Horowitz, A E Nyerges (Westview Press, Boulder, CO) pp 38-56

Smith N, 1984 Urban Development: Nature, Capital and the Production of Space (Blackwell, Oxford)

Smith W K, Tushman M L, 2005, "Managing strategic contradictions: A top management model for managing innovation streams" Organization Science $\mathbf{1 6}$ $522-536$.

Strauss A, Corbin J, 1998, Basics of qualitative research: Techniques and procedures for developing grounded theory. London: Sage.

Tan K Y, 2007, “China's 11th five-year plan: a critical perspective”, in China's Surging Economy: Adjusting for More Balanced Development Eds J Wong, W Liu (World Scientific, London) pp 55-132

Tushman M L, O'Reilly C, 1996, “Ambidextrous organizations: Managing evolutionary and revolutionary change" California Management Review 38 8-30.

Véron R, 2006, "Remaking urban environments: the political ecology of air pollution in Delhi” Environment and Planning A 38 2093-2109

While A, Jonas A, Gibbs D, 2004, "The environment and the entrepreneurial city: 
searching for the urban 'sustainability fix' in Manchester and Leeds" International Journal of Urban and Regional Research 28 549-569

Wong J, 2007, "China's economic growth in East Asian context", in China's surging Economy: Adjusting for More Balanced Development Eds J Wong, W Liu (World Scientific, London) pp 31-53

Xue M, Luo Y, 2015, "Dynamic variations in ecosystem service value and sustainability of urban system: A case study for Tianjin City, China” Cities 46 8593 
Figure 1. The mechanism of entrepreneurial infrastructuring

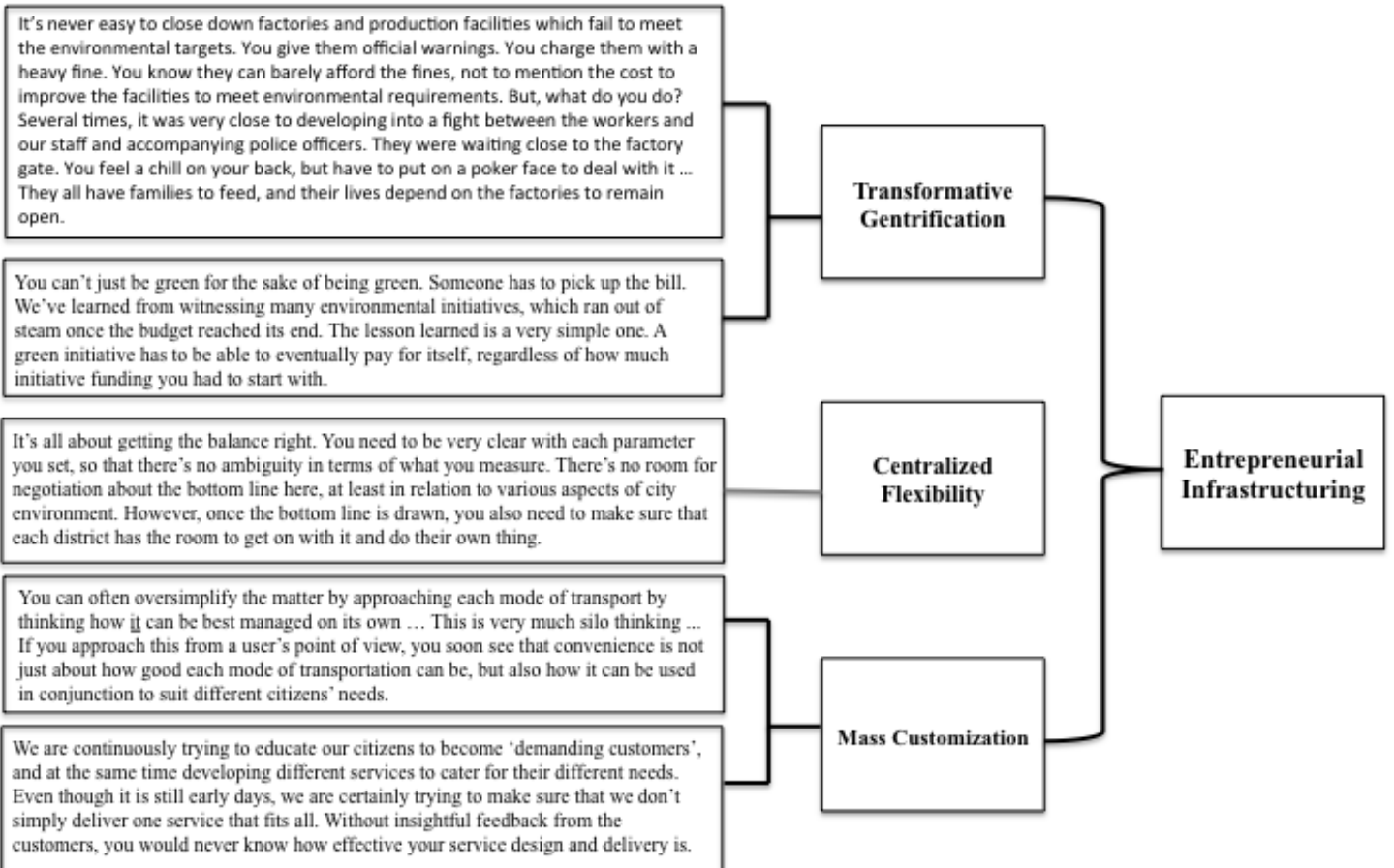


Figure 2. The mechanism of ecological momentum

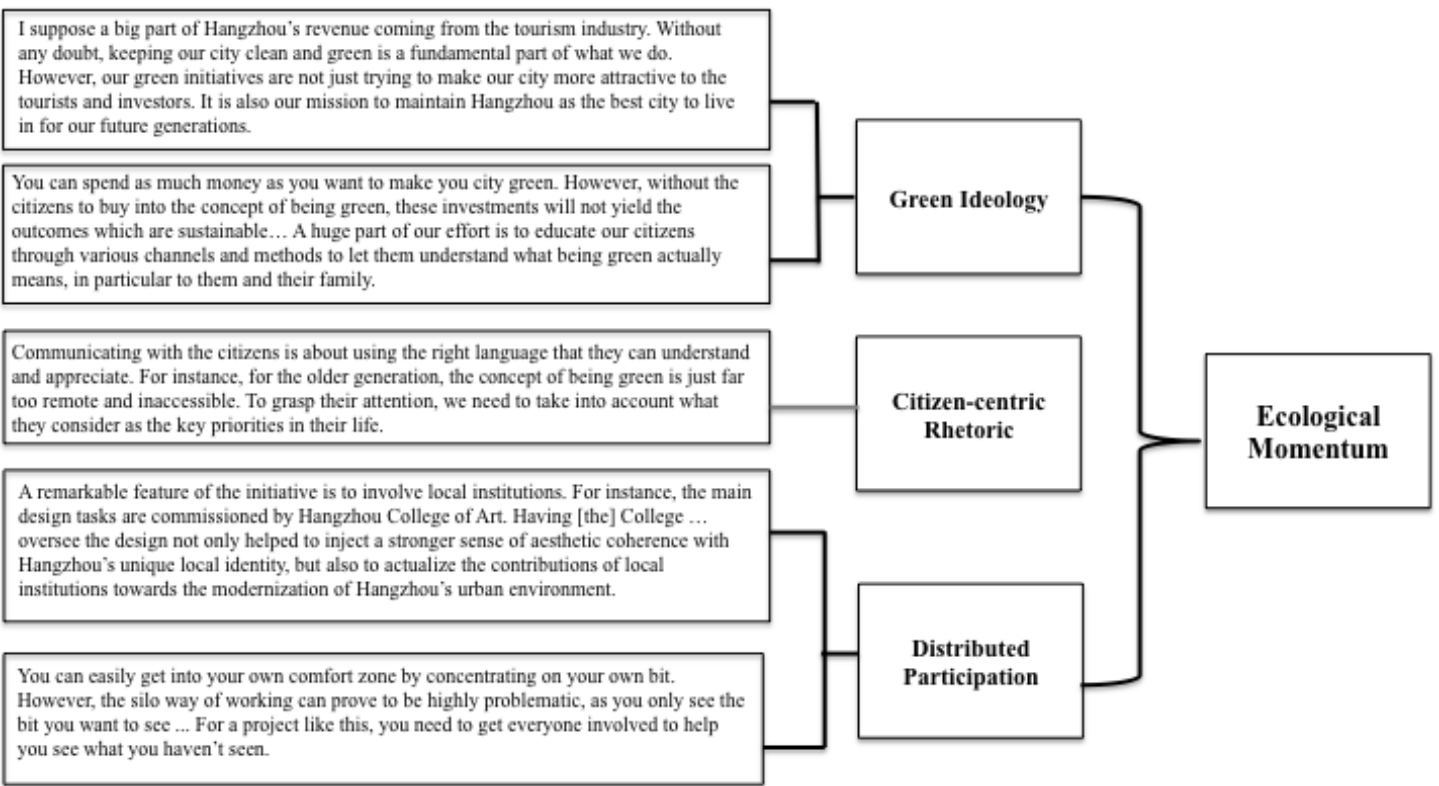

